\title{
The relationship between flow and electrolyte secretion in the canine pancreas
}

\author{
A. N. FAWCETT \\ From the Department of Surgery, Royal Infirmary, Sheffield
}

SUMMARY The response of the pancreatic bicarbonate secretory mechanism to secretin and the relationship between bicarbonate concentration and flow rate in pancreatic juice have been re-examined following reports describing decreasing levels of bicarbonate concentration at high flow rates. Both anaesthetized and chronic fistula dogs were used. The results show that when high doses of secretin elicit high rates of flow of pancreatic juice the bicarbonate concentration rises to a peak which is constant over a wide range of stimulation and flow rates.

Recent reports have cast doubts on the relationship established in earlier studies between anionic concentrations and the rate of secretion of pancreatic juice. It had been shown that bicarbonate concentration increases in a hyperbolic fashion with an increasing rate of flow of juice resulting in constant high bicarbonate concentrations at high flow rates whereas chloride concentrations show a converse relationship (Johnston and Ball, 1930; Bro-Rasmussen, Killmann, and Thaysen, 1956; Birnbaum and Hollander, 1965). However, the studies of Ribet, Pascal, Vaysse, and Boucard (1968) on anaesthetized dogs have shown that at high levels of stimulation the bicarbonate concentration falls as the flow rate increases so that a 'biphasic response' results. In man, too, the bicarbonate concentration has been found to decrease with an increasing flow rate over the entire range of flow rates achieved during secretin stimulation of the pancreas (Wormsley, 1968). The response of the pancreas to secretin has been re-examined in order to resolve these conflicting findings.

\section{Methods}

Two groups of animals were used in these experiments. The first consisted of anaesthetized dogs Received for publication 9 September 1969. which were sacrificed at the end of the experiment and the second group of conscious dogs with chronic pancreatic fistulae.

The dogs in the anaesthetized group were adult mongrels with weights ranging from 7.0 to $32.5 \mathrm{~kg}$. They were anaesthetized with pentobarbitone sodium, intubated, and maintained on spontaneous respiration using oxygen, nitrous oxide, and trichlorethylene. The pylorus was occluded by a ligature, the main pancreatic duct cannulated transduodenally after ligation of the accessory duct, and the common bile duct cannulated extraduodenally. Samples were collected into graduated tubes in an ice bath and stored at $4^{\circ} \mathrm{C}$ until the chemical estimations had been performed. Secretin was infused into a cannulated femoral vein.

The dogs with chronic fistulae consisted of six adult mongrels weighing from 12.5 to $25.0 \mathrm{~kg}$. Of these, two had Thomas cannulas in the duodenum through which the pancreatic duct could be cannulated under direct vision, and four had small duodenal pouches into which the pancreatic juice drained and which emptied via a metal tube into the duodenum. A cannula could be screwed into this metal tube to direct the juice to the exterior. All the chronic dogs had cannulas inserted into their stomachs to drain the gastric juice during an experiment. Before an experiment each dog was fasted overnight but not deprived of water. 
Secretin ${ }^{1}$ was dissolved in $0.9 \% \mathrm{NaCl}$ solution immediately before each experiment and was kept at $0^{\circ} \mathrm{C}$ during the course of the experiment. Appropriate quantities were injected using a constant-rate infusion pump delivering $84 \mathrm{ml} /$ hour.

The concentration of bicarbonate was estimated by adding $1 \mathrm{ml}$ of pancreatic juice to $2 \mathrm{ml}$ of $0.1 \mathrm{~N} \mathrm{HCl}$. This was then boiled to drive off carbon dioxide and the mixture titrated against $0.1 \mathrm{~N} \mathrm{NaOH}$ to $p \mathrm{H} 7.0$ using a Radiometer autotitrator. Chloride was estimated with an EEL chloride meter and osmolality with an Advanced osmometer.

\section{EXPERIMENTAL SCHEDULES}

\section{Response to increasing doses of secretin}

In this series six acute anaesthetized dogs were used and two experiments were performed on the chronic fistula dogs. Dose rates of secretin were doubled every 30 minutes although longer periods were sometimes necessary at low doses $(<1$ clinical unit $(\mathrm{cu}) / \mathrm{kg} / \mathrm{hr}$ ) to achieve steady flow. Four anaesthetized dogs received doses of $0.25 \mathrm{cu}$ per kilogram per hour to $8 \mathrm{cu} / \mathrm{kg} / \mathrm{hr}$. Two dogs received doses of $0.31 \mathrm{cu} / \mathrm{kg} / \mathrm{hr}$ to $10 \mathrm{cu} / \mathrm{kg} / \mathrm{hr}$ and one of these a further dose of $15 \mathrm{cu} / \mathrm{kg} /$ hour.

Two dogs in the chronic fistula group each received doses of $0 \cdot 25-16 \mathrm{cu} / \mathrm{kg} / \mathrm{hr}$ and dose rates were doubled every 20 minutes.

At doses above $1 \mathrm{cu} / \mathrm{kg} / \mathrm{hr}$ steady flow rates were usually obtained after 10 minutes of infusion and these readings have been denoted as 'steady state'. Readings obtained within the first 10 minutes of infusion of a given dose rate are denoted as 'non-steady state'. At doses below $1 \mathrm{cu} / \mathrm{kg} / \mathrm{hr}$ readings are only denoted as 'steady state' when a steady flow rate had been achieved. Other readings are denoted as 'non-steady state'.

\section{Response to decreasing doses of secretin}

In this series five anaesthetized dogs were used. Doses decreased geometrically from $64 \mathrm{cu} / \mathrm{kg} / \mathrm{hr}$ (in one dog), $16 \mathrm{cu} / \mathrm{kg} / \mathrm{hr}$ (in one dog) and $8 \mathrm{cu} / \mathrm{kg} /$ $\mathrm{hr}$ (in three dogs). In two experiments the decreasing doses were administered consecutively without any time lag between doses while in three experiments the rate of pancreatic secretion was allowed to fall to basal levels before the next lower dose was given.

\section{Response to separate single-dose infusions}

In this series five chronic fistula dogs were used. In each experiment a single-dose rate of secretin was given by constant intravenous infusion. The pancreatic juice was sampled at intervals ranging from three minutes at the higher doses to $10 \mathrm{~min}$ utes at the low doses. Chloride concentration was

'Obtained from the GIH Laboratory, Karolinska Institute, Stockholm. measured during the course of the experiment and the infusion of secretin was maintained until chloride had reached a minimum concentration and started to rise above this level. The time required for this ranged from 20 minutes with the high doses to one hour with the lowest doses. Each dog was given one or more tests at each dose and dose rates were doubled from 0.5 to $32 \mathrm{cu} /$ $\mathrm{kg} / \mathrm{hour}$.

\section{Response to prolonged continuous intravenous infusions}

Four dogs with chronic pancreatic fistulae were given continuous infusions lasting between four and six hours at doses of $0 \cdot 5,1,2$, and $4 \mathrm{cu} / \mathrm{kg} / \mathrm{hr}$. In a further series of four experiments the dogs were given an intravenous infusion of bicarbonate solution throughout the period of secretin stimulation. The amount of bicarbonate infused exceeded the amount of bicarbonate secreted by $12 \%, 36 \%, 87 \%$, and $127 \%$ respectively in the four experiments.

\section{Results}

INCREASING DOSE RESPONSE

Flow rate was related to the dose of secretin over the range tested. In five of the six dogs there was good correlation of flow rates between dogs when expressed as $\mathrm{ml} / \mathrm{kg}$ bodyweight/ min (Fig. 1). One dog had a higher rate of flow than the others when secretory rate was related to body weight.

The concentration of bicarbonate in the juice increased with increasing flow rates up to maximal values which ranged from 141 to 158 m-equiv/l. At higher flow rates the maximal concentration is not maintained but falls to lower levels (Fig. 2). The relationship between bicarbonate concentration and flow rate was similar in 'steady state' and 'non-steady state' secretion.

Low dose rates of secretin resulted in the secretion of juice with low bicarbonate concentrations, and, as the dose of secretin was increased, the concentration of bicarbonate rose to a maximum value which was found to occur at dose rates varying from 1 to $2.5 \mathrm{cu} / \mathrm{kg} /$ hour. At higher dose rates the concentration of bicarbonate fell to lower levels (Fig. 3).

Bicarbonate output increased linearly with increasing rate of flow of pancreatic juice except for a lesser rate of increase at higher dose rates in two dogs. Five of the dogs showed increasing output at all the doses of secretin employed while one dog showed a fall in output at high dose rates (Fig. 4). The increase in output between 4 and 8 units was not significant $(P=0 \cdot 15)$.

Changes in the concentration and output of chloride in pancreatic juice bore an inverse relationship to changes in the secretion of bi- 


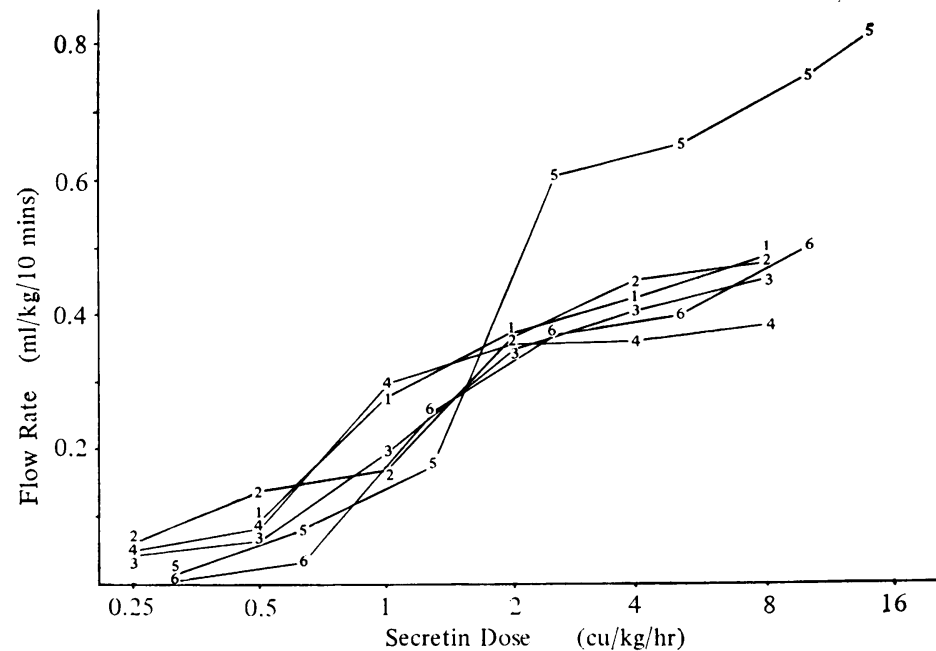

Fig. 1
Fig. 1 In five of the six dogs there is a good correlation between the dogs when the flow rate is expressed as ml/kg body weight. One dog had a higher rate of flow than the others.

Fig. 2 Because of the variation in flow rates and bicarbonate concentrations between dogs flow rates are expressed as a percentage of the flow rate at which maximal bicarbonate concentration was obtained and bicarbonate concentrations as percentages of that maximal value.

Fig. 3 The inverse relationship between bicarbonate and chloride concentrations is apparent.

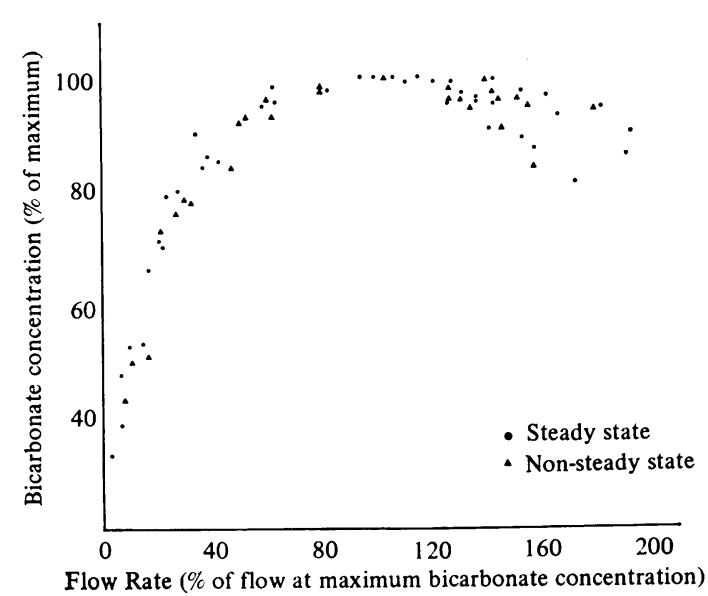

Fig. 2

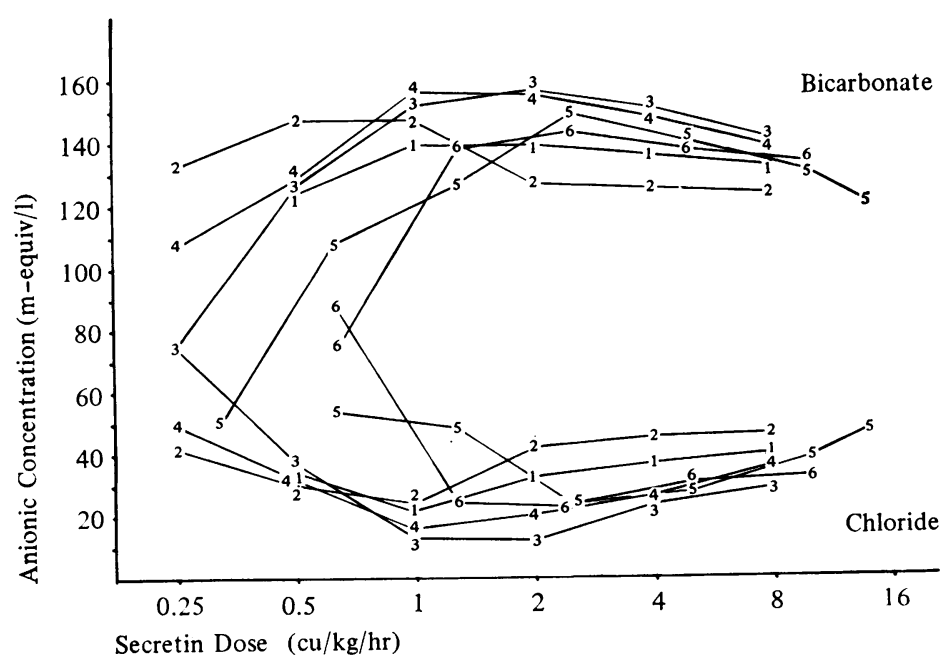

Fig. 3 carbonate. Low flow rates and low dose rates of secretin were associated with high chloride con- $\rightarrow$ centrations in the pancreatic juice which fell and then rose again in a biphasic manner as flow rates $\mathscr{\varrho}$ or dose rates of secretin increased (Figs. 3 and 5). $\vec{\bullet}$ The output of chloride was low with low doses of secretin and increased more rapidly at higher dose rates (Fig. 6).

The sum of the concentrations of bicarbonate and chloride ions varied with both flow rate and dose of secretin. The maximal value of the sum of the concentrations of the two anions occurred at flow rates greater than those associated with maximum bicarbonate concentrations. At lower flow rates the sum of $\mathbf{H C O}_{3}^{-}+\mathrm{Cl}^{-}$was significantly less (Fig. 7). The highest values for the sum of $\mathrm{HCO}_{3}^{-}+\mathrm{Cl}^{-}$occurred with a secretin dose of 2 or $2.5 \mathrm{cu} / \mathrm{kg} / \mathrm{hr}$ (Fig. 8). There was no significant change in the sum of the anions when the dose rate of secretin was increased further. The total anionic concentration was significantly less than maximal during infusion at low dose rates of secretin.

The osmolality of pancreatic juice was higher at flow rates corresponding to maximum bicarbonate concentration than at rates corre- 0 sponding to lower bicarbonate concentrations $N$ whether these occurred at low or high rates of $N$ flow (Fig. 9).

\section{DECREASING DOSE RESPONSE}

When the pancreas was stimulated initially with a large dose of secretin and subsequently by successive lower doses the highest concentrations of bicarbonate were obtained with the initial high dose of secretin. Lower concentrations were obtained during infusion at subsequent lower dose rates. The highest doses of secretin also elicited the highest flow rates. The relationship of bicarbonate to flow rate did not, therefore, show the biphasic response seen with increasing doses. 


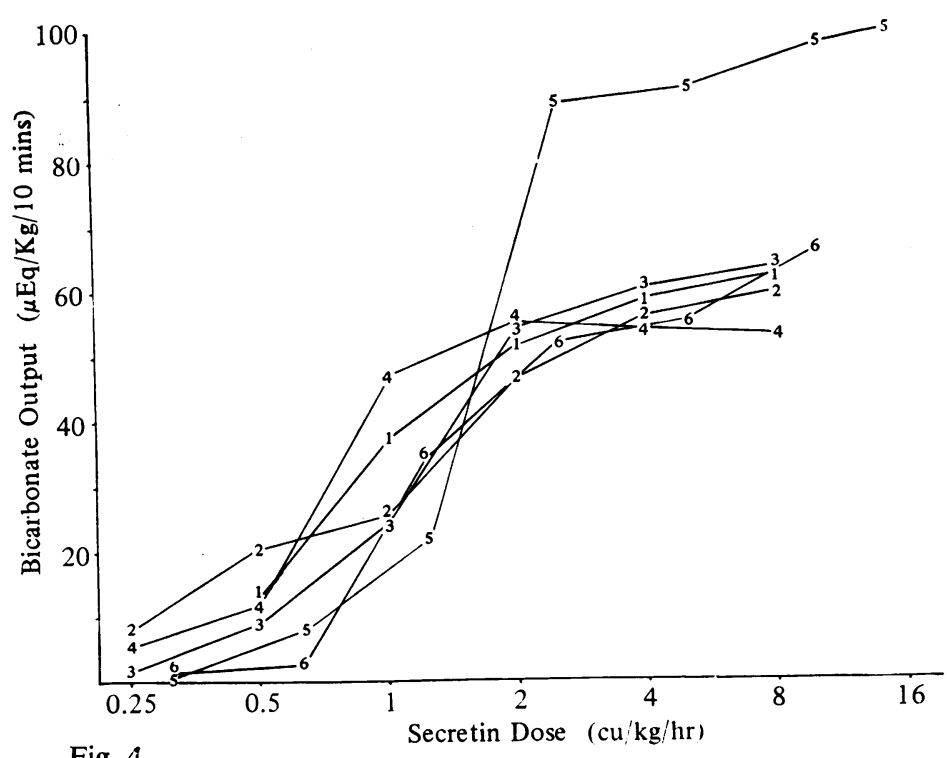

Fig. 4

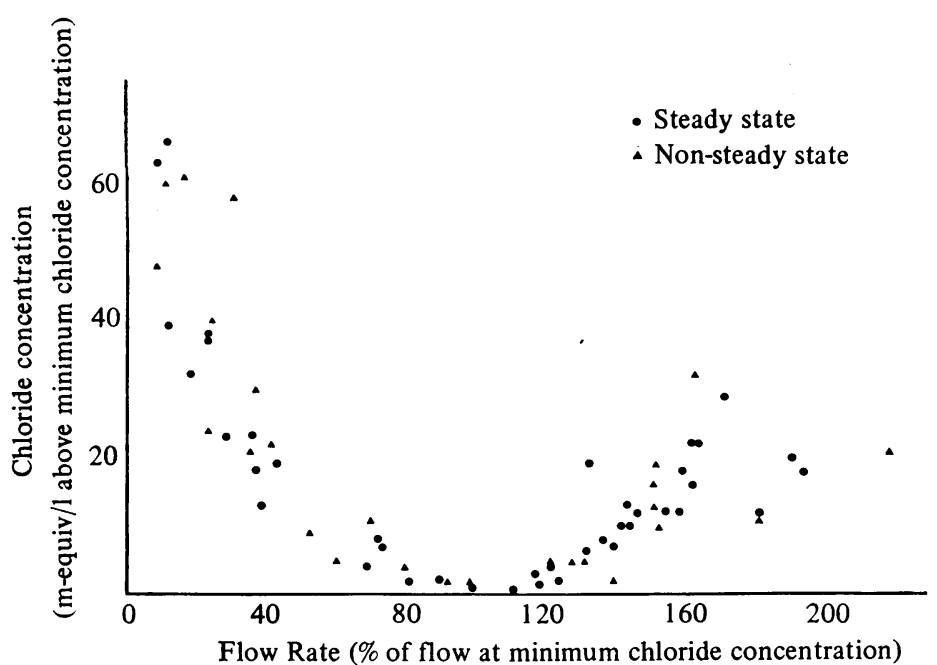

Fig. 5

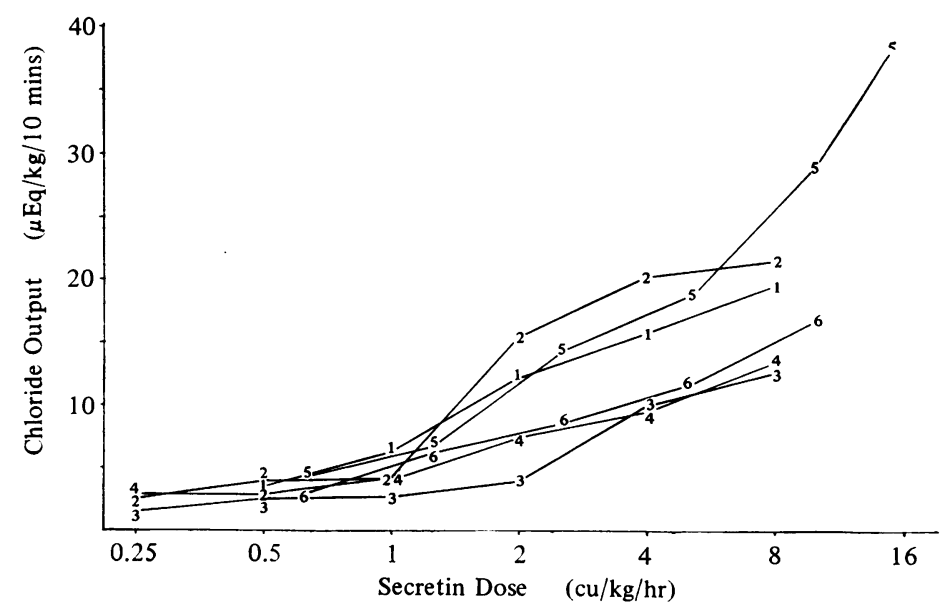

Fig. 6
Fig. 4 Bicarbonate output increased with increasing doses of secretin in all dogs except one in which maximal output was achieved at a dose of $2 \mathrm{cu} / \mathrm{kg} / \mathrm{hour}$. There was no significant increase at doses higher than $4 \mathrm{cu} / \mathrm{kg} /$ hour $(\mathrm{P}=0 \cdot 15)$.

Fig. 5 Because of variations in flow rates and chloride concentrations between dogs flow rates are expressed as percentages of the flow rate at which minimal chloride concentration was obtained and chloride concentrations in m-equiv/l above the minimum value in each test.

Fig. 6 Chloride output increases more rapidly at higher doses.
SEPARATE SINGLE-DOSE INFUSIONS

The rate of secretion of juice increased with increasing dosage of secretin. There was, in general, close agreement between flow rates produced by a given dose in separate tests in any one dog, especially in those dogs with duodenal pouches (Fig. 10). In the dogs with the Thomas type of fistula flow rates showed occasional marked variation. There was considerable variation in flow rates between different dogs stimulated at a given dose rate of secretin (Table).

Bicarbonate concentration rose in all tests from an initial low level to reach a peak from which it subsequently fell at a rate which varied with the infusion dose. The mean peak value for all tests was constant at all dose rates above the lowest (Fig. 11).

Chloride concentration bore an inverse relationship to bicarbonate concentration. There was no significant difference between the mean minimum values for all tests at any given dose rate of secretin above the lowest.

PROLONGED CONTINUOUS INFUSIONS

Infusion of secretin at a dose of $0.5 \mathrm{cu} / \mathrm{kg} / \mathrm{hr}$ resulted in wide fluctuations in flow rate over the period of the experiment. Bicarbonate concentration varied with flow rate, concentration being low at low rates of flow and rising with increases in rate of secretion. No definite decrease in bicarbonate concentration occurred over periods up to five and a half hours. With doses of $1 \mathrm{cu} / \mathrm{kg}$ / hr or higher a steady flow was achieved (Fig. 12).

Flow rate

Occasional fluctuations occurred in flow rate when the juice was collected over 10-minute periods. Hourly outputs show an increase over the first three hours $(P<0.01)$ and a steady rate thereafter (Fig 13). 


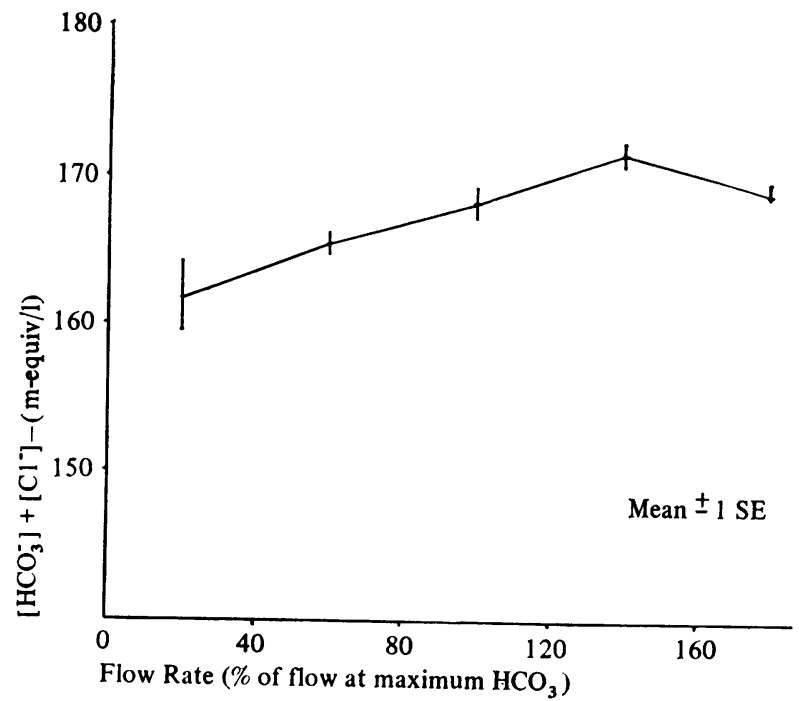

Fig. 7

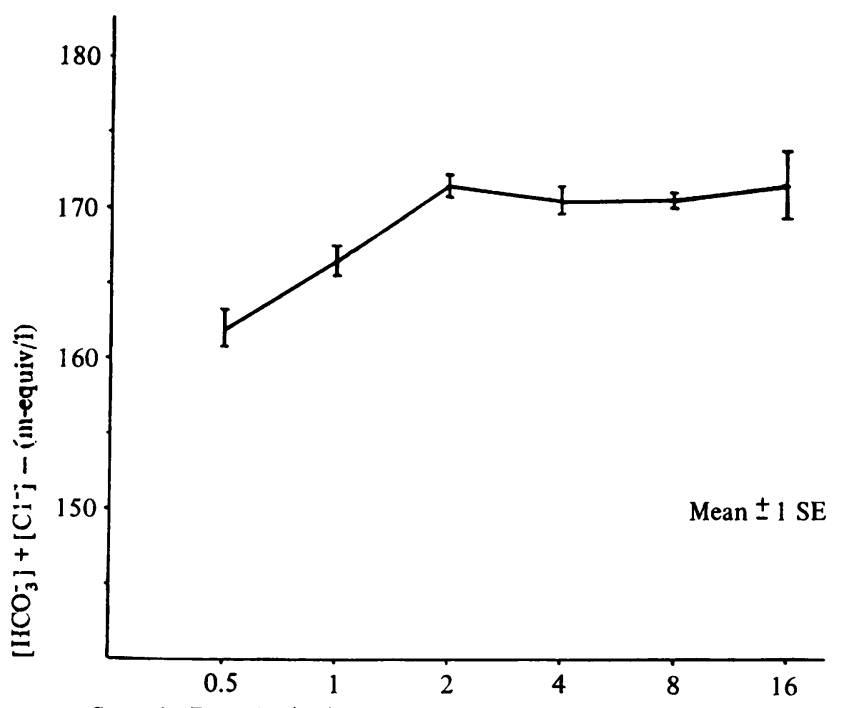

Secretin Dose $(\mathrm{cu} / \mathrm{kg} / \mathrm{hr})$

Fig. 8

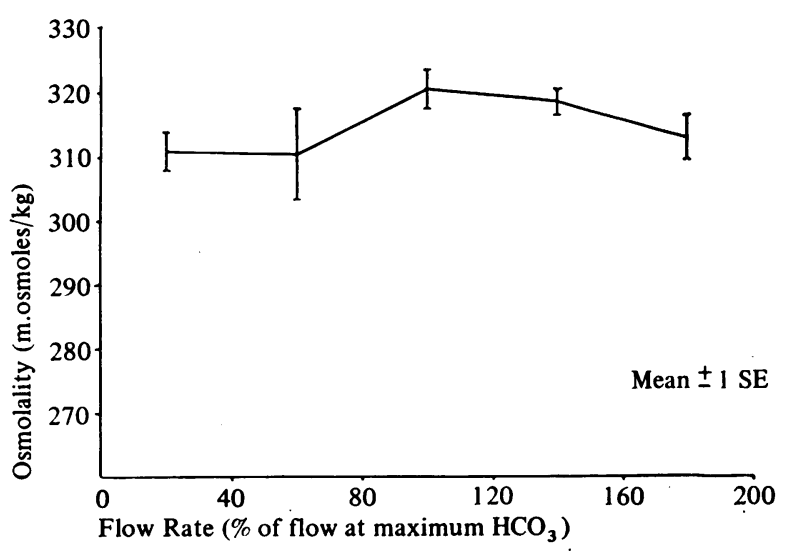

Fig. 9
Fig. 7 Flow rates are expressed as percentages of the flow rate at which maximum bicarbonate concentration was obtained in each experiment. Values for total anionic concentration were analysed in groups, each group corresponding to $40 \%$ increases in flow rate. Significant differences were found between successive groups. Between 0 and 40 and 40 and 80P $=0.0039,40-80$ and 80-120 $\mathrm{P}=0.025$, $80-120$ and 120-160 $\mathrm{P}=0.0007$, and 120-160 and $160-200 \mathrm{P}=0.035$.

Fig. 8 Six experiments in anaesthetized dogs. Total anionic concentration remains unchanged with increasing secretin doses above $2 \mathrm{cu} / \mathrm{kg} / \mathrm{hour}$. Comparing each dose with the previous lower dose, for $1 \mathrm{cu}, \mathrm{P}=0.00003,2 \mathrm{cu}, \mathrm{P}=0.0009,4 \mathrm{cu}, \mathrm{P}=$ $0 \cdot 206$, and $8 \mathrm{cu}, \mathrm{P}=0 \cdot 28$.

Fig. 9 Flow rate is expressed as a percentage of the flow rate at which maximal bicarbonate concentration was obtained in each experiment. Osmolality was significantly higher at flow rates between $80-160 \%$ than at flow rates below $40 \%$. At flow rates greater than $160 \%$ osmolality fell significantly. Comparing the groups and denoting successive $40 \%$ increments as 1-5, $\mathrm{P}$ values are: Comparing 1 with $2 \mathrm{P}>0.05,1$ with $3 \mathrm{P}=0.025,2$ with 3 $\mathrm{P}>0.05,1$ with $4 \mathrm{P}=0.0069,3$ with $4 \mathrm{P}=0.48$, 1 with $4 \mathrm{P}=0.57,4$ with $5 \mathrm{P}=0.021$, and 2 with 4 $\mathrm{P}=0.07$.

\section{Bicarbonate concentration}

In all tests at doses of $1 \mathrm{cu} / \mathrm{kg} / \mathrm{hr}$ or higher, bicarbonate concentration rose rapidly from basal levels to reach maximal values within 20 minutes. These values were maintained for periods up to 30 minutes and then decreased. In one dog the rate and extent of the decrease appeared to be related to the secretin dose but there was no correlation in the other dogs. The decrease continued for a period of three to four hours and then stopped (Fig. 12).

\section{Bicarbonate output}

Bicarbonate output remained constant during the first three hours of infusion. In the fourth hour there was a small but significant fall $(P<0.01)$ but output then levelled off again (Fig. 14).

\section{Chloride concentration}

The concentration of chloride bore an inverse relationship to bicarbonate concentration, falling from high basal levels to low minimal values which were maintained for a period of up to 30 minutes before increasing (Fig. 12). 


\begin{tabular}{|c|c|c|c|c|c|c|c|c|}
\hline \multirow[t]{2}{*}{ Dog } & \multirow[t]{2}{*}{ Body Weight (kg) } & \multicolumn{7}{|c|}{ Mean Flow Rate $(\mathrm{ml} / 10 \mathrm{~min})$} \\
\hline & & \multicolumn{5}{|c|}{ Secretin Dose $(\mathrm{cu} / \mathrm{kg} / \mathrm{hr})$} & $16 \cdot 0$ & $32 \cdot 0$ \\
\hline B & $14 \cdot 0$ & 6.4 & $9 \cdot 5$ & $12 \cdot 7$ & $14 \cdot 0$ & $13 \cdot 2$ & $14 \cdot 4$ & 14.9 \\
\hline $\mathbf{F}$ & 18.0 & $8 \cdot 7$ & $9 \cdot 7$ & $15 \cdot 5$ & 15.5 & $17 \cdot 0$ & 17.0 & $17 \cdot 5$ \\
\hline J & 12.5 & 6.4 & 8.0 & $9 \cdot 4$ & $10 \cdot 5$ & 10.9 & $9 \cdot 0$ & 10.0 \\
\hline $\mathbf{N}$ & 25.0 & $5 \cdot 3$ & $9 \cdot 3$ & $12 \cdot 7$ & 12.5 & 14.7 & $14 \cdot 0$ & $13 \cdot 5$ \\
\hline $\mathbf{S}$ & 14.0 & 9.0 & 12 & 15.6 & $16 \cdot 3$ & $18 \cdot 7$ & $18 \cdot 6$ & $20 \cdot 1$ \\
\hline
\end{tabular}

Table Flow rates in five dogs after stimulation by varying doses of secretin

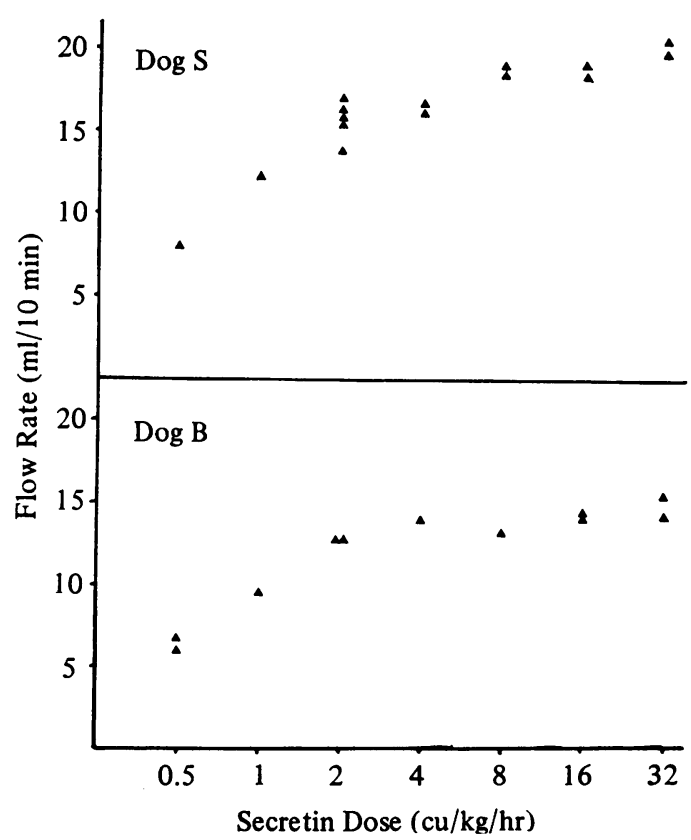

Fig. 10 Flow responses to single dose infusions in two dogs with duodenal pouches. There is good correlation between flow rates at a given dose in different tests.

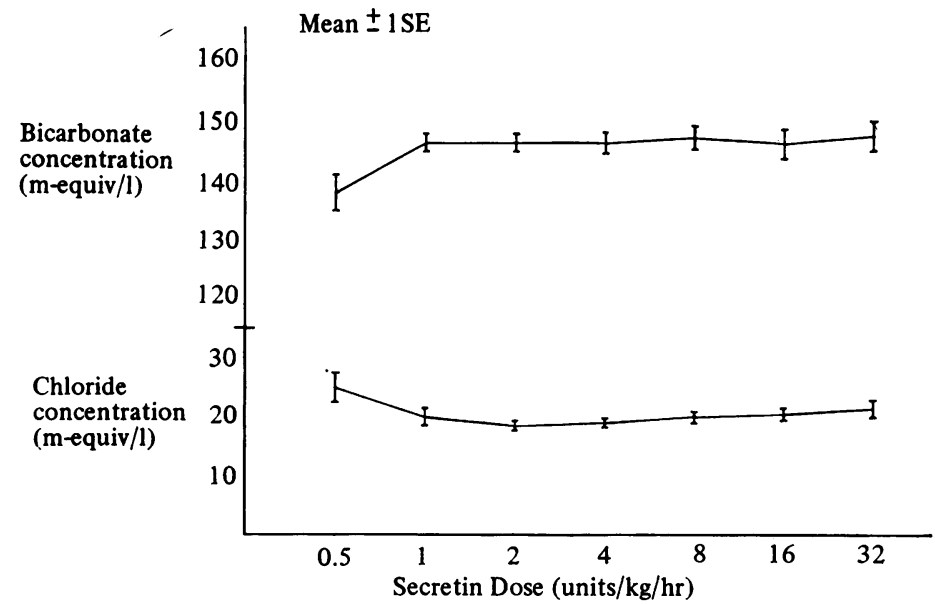

Fig. 11 Results of 52 experiments in five dogs with chronic duodenal fistulae. The dogs were given multiple single-dose infusions and the maximum value for bicarbonate concentration and minimum value of chloride concentration plotted against secretin dose.

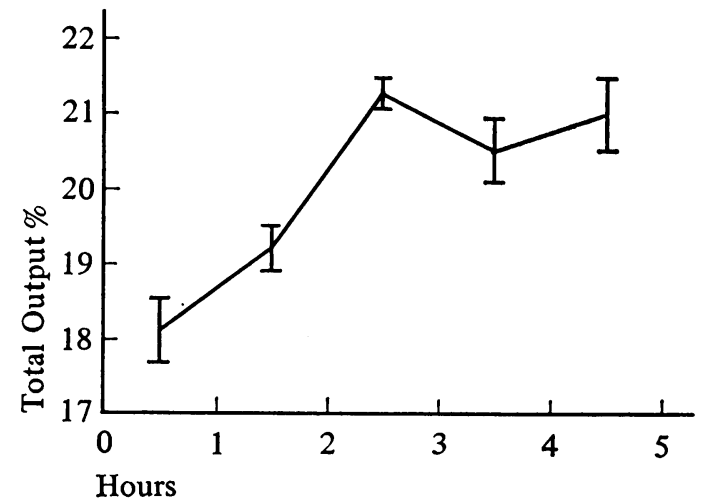

Fig. 12 The pancreatic response to a five-hour intravenous infusion of secretin $2 \mathrm{cu} / \mathrm{kg} / \mathrm{hr}$. 'Anions' = sum of bicarbonate + chloride concentrations. Blocked lines represent outputs, Dotted lines represent concentrations.

Fig. 13 Hourly outputs of pancreatic juice during prolonged constant-dose infusion. The first hourly output is extrapolated from the output in the last 40 minutes of the hour when the flow has become 'steady'. Percentages of total five-hour output are shown for 16 tests. Points represent means \pm 1 SE. Output rises over the first three hours $(\mathrm{P}<0.01)$. 


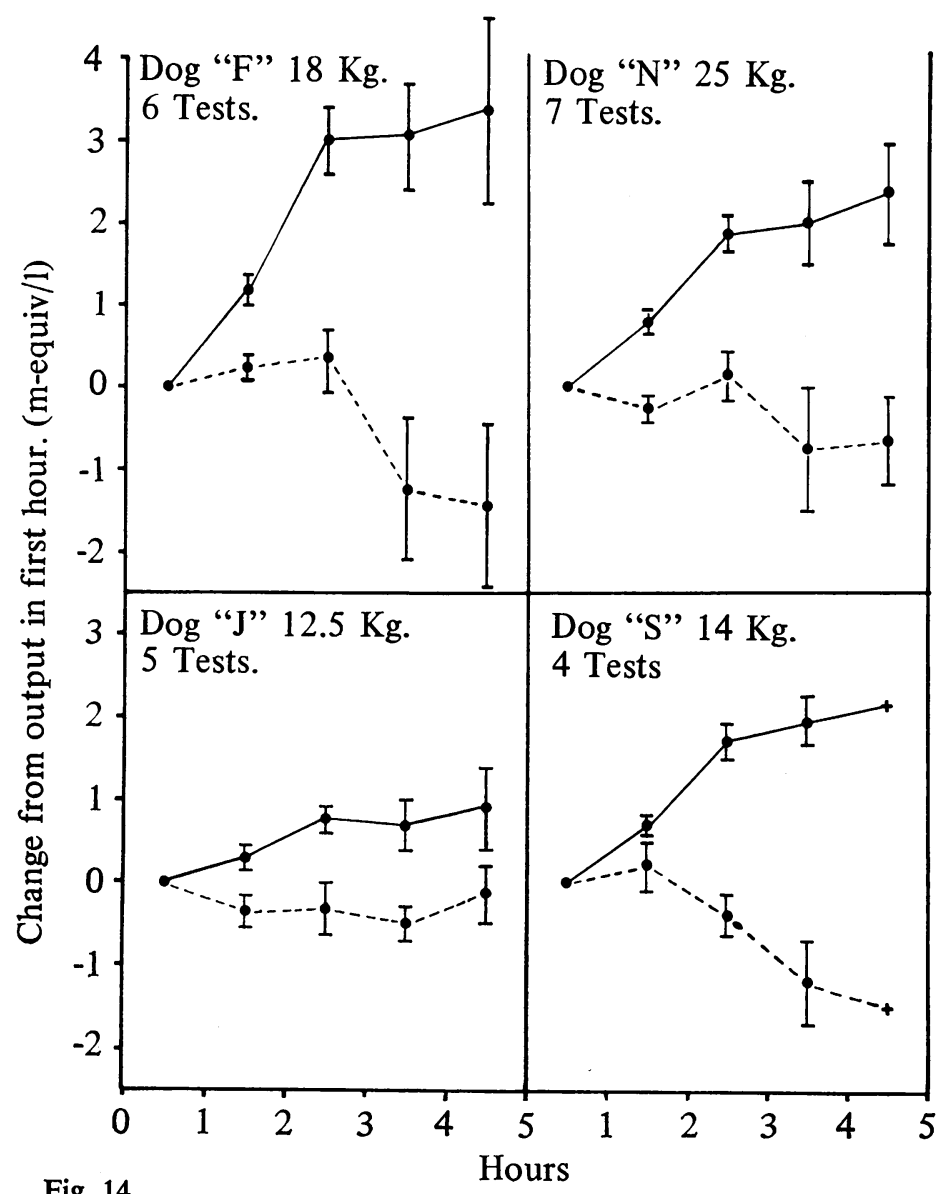

Fig. 14

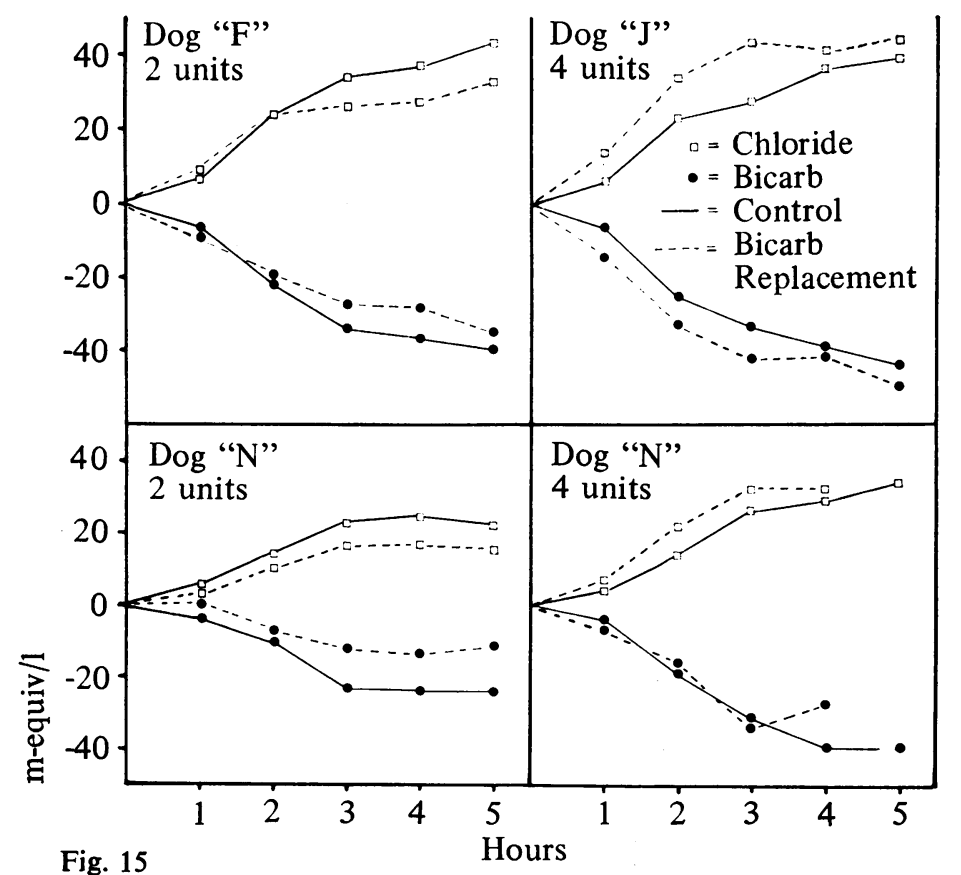

Fig. 14 Hourly outputs of bicarbonate and chloride. Output in the first hour is extrapolated from the output in the last 40 minutes in the hour and subsequent outputs are shown relative to this. Points represent means $\pm 1 S E$. Continuous line represents chloride, broken line represents bicarbonate.

Fig. 15 Changes in ionic concentration during prolonged secretin infusion with and without intravenous bicarbonate and chloride replacement. Bicarbonate replacement does not prevent the changes in ionic concentration. Each figure represents one test with and one without bicarbonate replacement.

\section{Chloride output}

There was an increase in chloride output during the first three hours of stimulation $(P<0.01)$. After this time no further increase in output occurred. The period of increasing output corresponded with the period during which the bicarbonate concentration fell (Fig. 14).

\section{Total anionic concentration}

The sum of bicarbonate and chloride concentrations showed a slight diminution during the course of the stimulation (Fig. 12).

\section{Osmolality}

No change occurred throughout each experiment.

\section{Protein output}

Low and variable protein outputs were obtained and no constant pattern emerged.

Urea

The concentration of urea in the pancreatic juice remained constant or diminished during the course of the experiment.

When bicarbonate was infused intravenously the pattern of change of anionic concentration showed no difference from that observed in control experiments without bicarbonate replacement at the same secretin dosage (Fig. 15).

\section{Discussion}

Many investigators have found a 'hyperbolic' relationship between bicarbonate concentration in pancreatic juice and the rate of secretion of the juice in the dog (Hart and Thomas, 1945; Bro-Rasmussen et al, 1956), in the cat (Case,

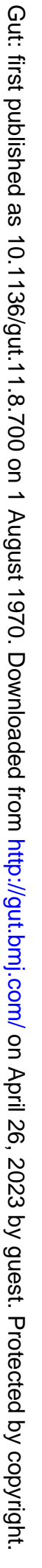




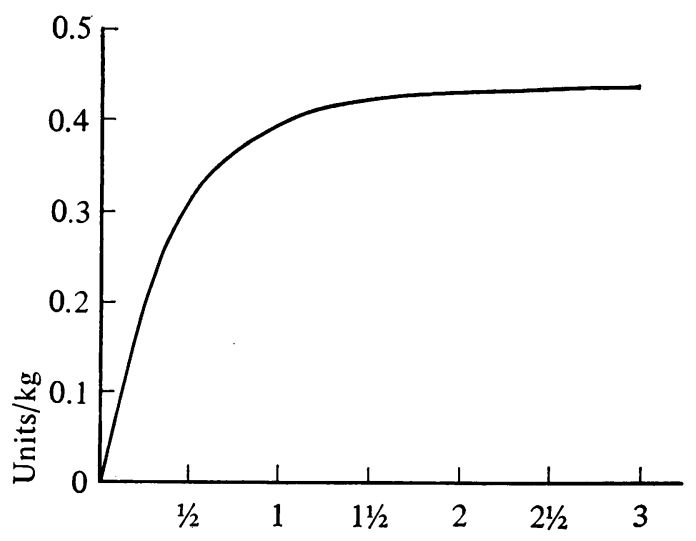

Hours

Fig. 16 The change in secretin level in the body during a constant dose infusion. Calculation from the equation.

$$
Q=1 \cdot 44 \lambda H i\left(1-e \frac{-t}{1 \cdot 44 \lambda H}\right) \text { where }
$$

$Q=$ concentration in the body, $i=$ infusion dose, $t=$ time after start of infusion and $\lambda H$ is assumed to be $18 \mathrm{~min}$ (after Lagerlöf et al, 1962).

Harper, and Scratcherd, 1966), and in man (Lagerlöf, 1962; Janowitz and Dreiling, 1962). Recently Ribet et al (1968) have shown that in the dog at high levels of stimulation bicarbonate concentration fell with increasing flow rate to give a 'biphasic response'. Wormsley (1968) and Ribet, Pascal, and Sannou (1967) have also shown that in man bicarbonate concentration in duodenal aspirate decreases as flow rate increases in response to fairly high doses of secretin. The results of the present experiments have confirmed the biphasic response of bicarbonate concentration with increasing flow rate but only under certain experimental conditions. If increasing doses are used consecutively, as they were in the present study and in that of Ribet et al(1968), a biphasic curve is produced. If, however, the doses are used in the reverse order so that high doses are used initially and followed by lower doses the same results are not obtained but the resultant relationship resembles a hyperbola. Moreover high doses of secretin given for short periods of time only do not elicit lower bicarbonate concentrations than lower dose rates.

It seems that, under conditions of previous stimulation with lower doses of secretin, or alternatively, previous stimulation of the pancreas over a prolonged period of time, the secretion of bicarbonate becomes associated with the secretion of chloride so that the volume of juice increases and the concentratiun in bicarbonate falls despite constant bicarbonate output. This phenomenon is not due to anaesthesia since it has been demonstrated in conscious dogs. Likewise it is not due to a depletion of bicarbonate in the plasma. Komarov, Langstroth, and McRae (1939) demonstrated that the fall in bicarbonate concentration was not influenced by simultaneous intravenous replacement of bicarbonate ions and this result has been confirmed in the present study.

Komarov, Langstroth, and McRae (1939) and later Christodoulopoulos, Jacobs, and Klotz (1961) showed that if a pancreas was stimulated by a constant-dose infusion of secretin the flow rate of pancreatic juice remained constant for several hours but that after a brief initial plateau the bicarbonate concentration and output began to fall. Baron, Perrier, Janowitz, and Dreiling (1963) noted that continuous infusion of secretin led to a fall in bicarbonate concentration independent of flow rate after a period varying from 30 to 100 minutes in different dogs. On the other hand, Case et al (1969) found that the pancreas of the anaesthetized cat could maintain a constant bicarbonate concentration during prolonged stimulation.

Christodoulopoulos et al (1961) attributed the fall in bicarbonate concentration to 'exhaustion' of the pancreas. The present study has shown that the cause of the fall in bicarbonate concentration is the secretion of sodium chloride by the pancreas. There is noevidence of 'exhaustion' of the pancreas since the output of bicarbonate remains constant at the time when the concentration falls, but during this period the volume and output of chloride are both increasing. Similarly analysis of the data presented by Christodoulopoulos et al (1961) shows that the volume of pancreatic juice increased for five hours and that bicarbonate output remained constant.

The source of the chloride secreted during prolonged stimulation remains unknown. Four possibilities are considered.

1 The extra secretion is primarily a bicarbonate solution produced in response to accumulating levels of secretin in the body. Lagerlöf, Ek, and Nyberg (1962) have calculated a 'biological half life' for secretin of 18 minutes. Using this value to calculate the levels in the body it can be shown that a near equilibrium state is reached, for a constant dose infusion, after a period of about one and a half hours (Fig. 16). This could explain the increase in flow rate over the initial period of infusion observed in the present study. If we assume that the extra secretion is primarily a bicarbonate solution there must be, at the same time, increased ductal exchange of bicarbonate for chloride so that the eventual output of bicarbonate remains unchanged. The higher exchange could not, however, be due only to the level of secretin since it has been shown that increasing doses of secretin (of $1 \mathrm{cu} / \mathrm{kg} / \mathrm{hr}$ and above) are associated with constant concentra- 
tions of bicarbonate and chloride when given for short periods only. Thus the higher exchange could only be explained in terms of a progressive alteration in ductal anionic exchange mechanisms associated with the passage of time.

Ribet et al (1968) suggested that the secretion of the pancreas consisted of two components comprising a bicarbonate and a chloride fraction each secreted under the influence of secretin but unequally sensitive to secretin. This explanation does not fit the present facts as the dilution phenomenon was independent of the dose of secretin.

2 The extra secretion is composed of sodium chloride due, perhaps, to a progressive acidosis caused by the secretion of large amounts of bicarbonate by the pancreas. Rawls, Wistrand, and Maren (1963) found that a metabolic acidosis produced by infusing hydrochloric acid intravenously reduced pancreatic flow and bicarbonate output very considerably. However, Komarov et al (1939) found that replacing the secreted bicarbonate by a separate intravenous infusion did not prevent the fall in bicarbonate concentration of the pancreatic juice and the same result has been demonstrated in this study.

3 The added secretion could be a transudate from the extracellular fluid. The effect of secretin on pancreatic blood flow is still disputed but the balance of evidenceindicates that secretin increases blood flow (Jones, 1960). The increase in blood flow may be secondary to increased intraduct pressure, as described by Bennett and Still (1933), or due to vasodilator kinins liberated during active pancreatic secretion as suggested by Hilton and Lewis (1955). Whatever the relative importance of these or other mechanisms the overall result of secretin stimulation could increase transudation. However, the extra chloride in the pancreatic juice is not associated with the appearance of increased urea concentrations in the juice so that there is no simple leakage of extracellular fluid.

4 Case et al (1969) have shown that protein is secreted by the pancreas in a chloride-containing solution. In the present study the protein output was low and variable and bore no constant relationship to chloride output.

None of these models explains satisfactorily the origin of the sodium chloride which appears in pancreatic juice during prolonged stimulation. It appears that dose of secretin, and therefore blood secretin levels, are relatively unimportant and that time is a more important factor. This would suggest either a chloride secretory mechanism which requires a considerable time for full activation or, more likely, a progressive change in the intracellular milieu with the accumulation of chloride ions which find their way more easily into the pancreatic secretion than into the extracellular fluid. Further clarification of this phenomenon may follow improvement in micro- puncture techniques and the introduction of techniques for measuring changes in the blood levels of secretin during prolonged infusion.

I wish to thank Professor H. L. Duthie and Dr K. G. Wormsley for constant interest, help and encouragement, and Mr F. D. Naylor for his invaluable help in preparing the experimental animals and in the experiments themselves. I am indebted to the staff of the photographic department for help with the illustrations and to Mrs A. Berney for secretarial assistance.

This work was supported in part by a generous grant from the Endowment Fund of the United Sheffield Hospitals.

\section{References}

Baron, J. H., Perrier, C. V., Janowitz, H. D., and Dreiling, D. A. (1963). Maximum alkaline (bicarbonate) output of the dog pancreas. Amer. J. Physiol., 204, 251-256.

Bennett, A. L., and Still, E. U. (1933). A study of the relation of pancreatic duct pressure to the rate of blood flow through the pancreas. Amer. J. Physiol., 106, 454-459.

Birnbaum, D., and Hollander, F. (1965). Relation between bicarbonate concentration and rate of canine pancreatic secretion. Amer. J. Physiol., 209, 966-972.

Bro-Rasmussen, F., Killmann, S. A., and Thaysen, J. H. (1956). The composition of pancreatic juice as compared to sweat, parotid saliva and tears. Acta physiol. scand., 37, 97-113.

Case, R. M., Harper, A. A., and Scratcherd, T. (1966). The relationship between bicarbonate and chloride in pancreatic juice. J. Physiol. (Lond.), 182, 49-50P.

Christodoulopoulos, J. B., Jacobs, W. H., and Klotz, A. P. (1961). Action of secretin on pancreatic secretion. Amer. $J$. Physiol., 201, 1020-1024.

Hart, W. M., and Thomas, J. E. (1945). Bicarbonate and chloride of pancreatic juice secreted in response to various stimuli. Gastroenterology, 4, 409-420.

Hilton, S. M., and Lewis, H. P. (1955). The mechanism of the functional hyperaemia in the submandibular salivary gland. J. Physiol. (Lond.), 129, 253-271.

Janowitz, H. D., and Dreiling, D. A. (1962). The pancreatic secretion of fluid and electrolytes. In Ciba Foundation Symposium on the Exocrine Pancreas, edited by A. V. S. de Reuck and M. P. Cameron, pp. 115-133. Churchill. London.

Johnston, C. G., and Ball, E. G. (1930). Variations in inorganic constituents of the pancreatic juice during constant drainage of the pancreatic ducts. J. biol. Chem., 86, 643 . 653.

Jones, M. (1960). The effect of secretin on pancreatic blood flow. J. Physiol. (Lond.), 151, 49-50P.

Komarov, S. A., Langstroth, G. O., and McRac, D. R. (1939) The secretion of crystalloids and protein material by the pancreas in response to secretin administration. Canad. J. Res., 17, 113-123.

Lagerlö, H. O. (1962). Pancreatic Function and Pancreatic Disease, p. 66. Norstadt and Soner, Stockholm.

Lagerlöf, H., Ek, S. Y., and Nyberg, A. (1962). The duodenal secretion in man as a function of secretin dose and secretin inactivation. Gastroenterology, 43, 174-180.

Rawls, J. A., Jr., Wistrand, P. J., and Maren, T. H. (1963). Effects of acid-base changes and carbonic anhydrase inhibition on pancreatic secretion. Amer. J. Physiol., 205, 651-657.

Ribet, A., Pascal, J. P., Vaysse, N., and Boucard, J. P. (1968). Relationship between bicarbonate, chloride, and volume flow at high secretory rates in the pancreatic juice of the dog. Scand. J. Gastroent., 3, 401-406.

Ribet, A., Pascal, J. P., and Sannou, N. (1967). Etude de 18 fonction exocrine du pancréas humain par les perfusions continues de sécrétine. I. Influence des doses croissantes sur la sécrétion hydro-electrolytique. Arch. franc. Mal. App. dig., 56, 677-684.

Wormsley, K. G. (1968). Response to secretin in man. Gastroenterology, 54, 197-209. 